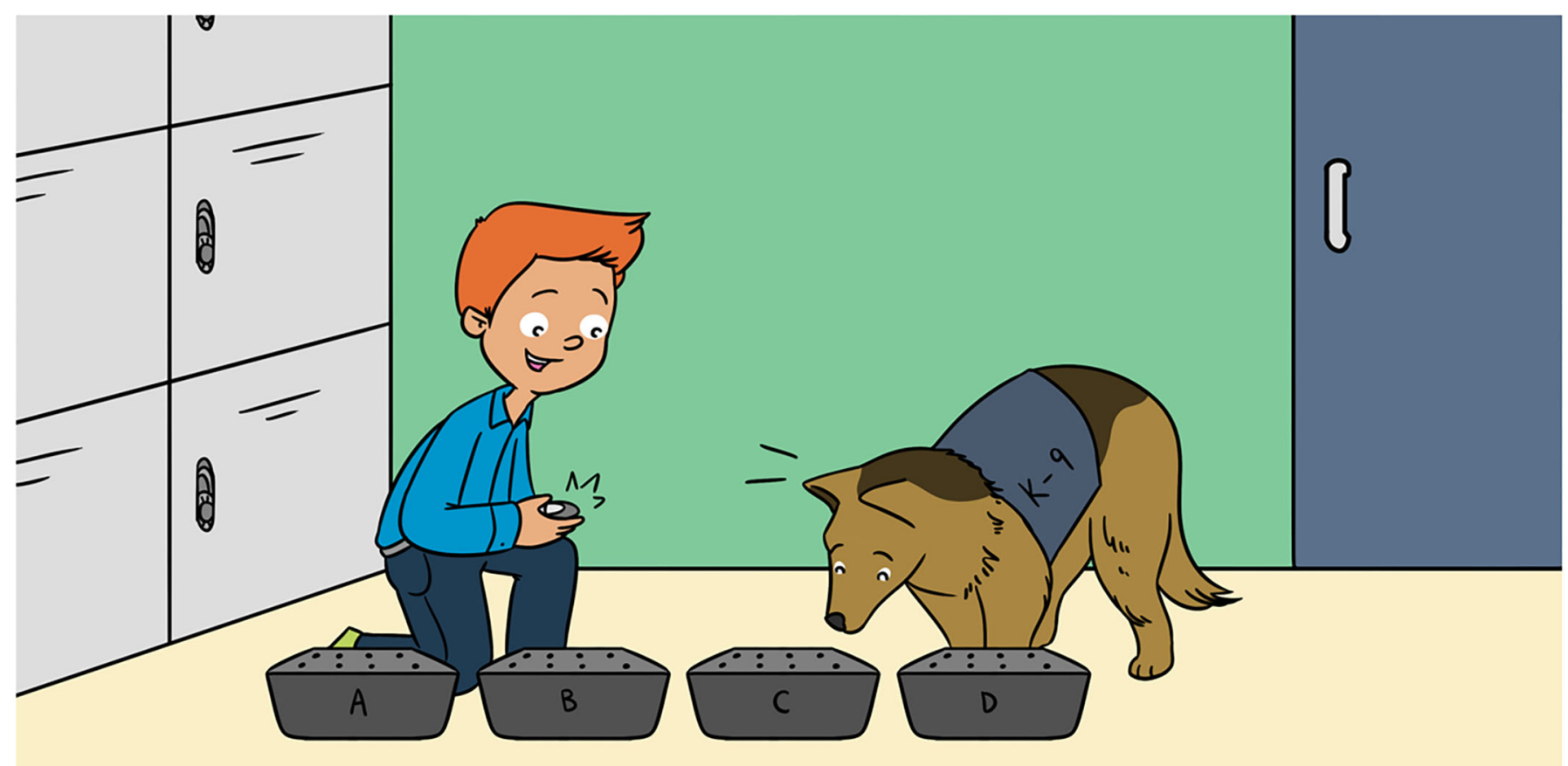

\title{
HOW DO POLICE DOGS LEARN TO DO THEIR JOB?
}

\section{Sara V. R. Jones and Valerie A. Kuhlmeier *}

Department of Psychology, Queen's University, Kingston, ON, Canada

YOUNG REVIEWERS:

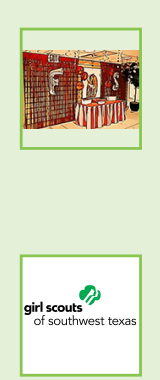

FRIENDS

SEMINARY

AGES: $11-13$

GIRL

SCOUTS OF

SOUTHWEST

TEXAS,

TROOP 66

AGES: 8-13

JOSEPHINE

AGE: 12

LAUREN

AGE: 13

MAHOGANY

AGE: 11
Dogs have been working with humans for thousands of years. Nowadays, we have very important jobs for dogs, like helping blind people to walk safely in a city or helping a police officer to find something dangerous. But how do dogs learn to do their jobs? In this article, you will learn about animal learning. Specifically, we will focus on how police dogs learn to tell us where something is hidden, using their powerful sense of smell.

You may have seen guide dogs, police dogs, and support dogs when you were out and about. The jobs these dogs do can be very important to us, like when a police dog (Figure 1) is able to use its nose to find something dangerous or to find someone who is lost. How do these dogs learn to do their jobs?

\section{DOGS PAY ATTENTION TO US AND LEARN FROM US}

Of all the different types of animals, dogs are unique in how well they work with us. Many thousands of years ago, dogs started helping humans to hunt, guard our herds of sheep, and protect our homes. 
Figure 1

A police dog (Photo by Michael Pereckas: https://www.flickr.com/ photos/53332339aNOO/ 2853844526; Licensing agreement: https:// creativecommons. org/licenses/by/2.0/deed .en).

\section{DOMESTICATION}

Over many generations, animals come to live with humans, and in some cases, work alongside us.

\section{ASSOCIATION}

A learned relationship between events or behaviors. For example, learning that the sound of a doorbell means there is someone at the door, or that doing a bad behavior might lead to a time-out.

\section{POSITIVE}

\section{REINFORCEMENT}

When a behavior (for example, sitting) produces a positive outcome (a treat), the behavior will be encouraged and is more likely to be repeated.

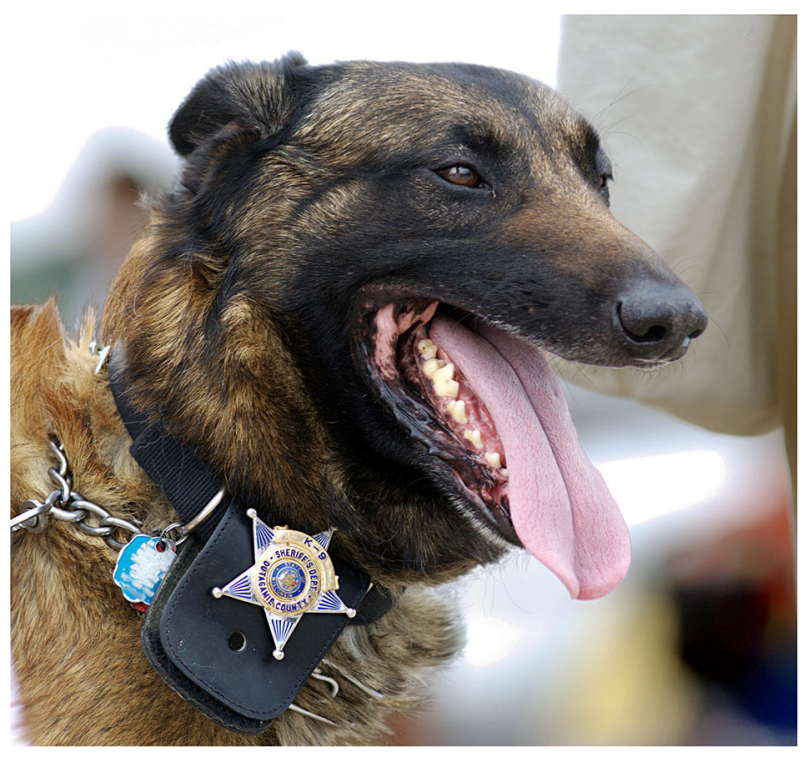

Figure 1

In return, humans provided shelter and food for the friendliest and best-working dogs and their puppies.

Nowadays, you can see the results of thousands of years of dogs living with humans, something scientists call domestication. For example, dogs pay more attention to humans than their wild wolf relatives do. Dogs watch where we go, as well as where we look and point [1]. Because dogs are so interested in us, we can train them to do a variety of behaviors-and they are very eager learners.

\section{DURING TRAINING, DOGS LEARN ASSOCIATIONS}

Maybe you know a dog that has been trained to understand commands, such as sit, roll over, or shake a paw. Dogs do not naturally do these behaviors when told. Instead, they had to learn to connect the words we say ("Sit!") with the right behavior that gets them a treat (sitting). When we train them properly, dogs are good at learning that some of the words we say are associated with certain actions and rewards. This is why dogs are helpful in many different jobs.

Scientists who study psychology understand a lot about how dogs learn to make associations between our words and their actions, such as sitting after hearing the word "Sit!" in order to get a reward. If trainers repeatedly reward a behavior like sitting with food or a toy, then a dog will do the behavior more and more. Psychologists call this process positive reinforcement, because a behavior becomes encouraged or reinforced when it leads to a positive outcome, like a toy (you can probably imagine the opposite of positive reinforcement: punishment!). 


\section{SOME POLICE DOGS ARE TRAINED TO TELL US WHERE THINGS ARE HIDDEN}

Teaching dogs associations is one way that trainers help dogs learn to do their jobs. We can understand more about animal learning by looking closely at police dogs. For example, how are police dogs trained to tell their human partners when they have smelled something important? This is more complicated than learning to sit, but it is based on the same basic learning processes.

Police dogs can do something that their human partners cannot often do: they can locate important things just by smell (Figure 2). Dogs can sniff out dangerous or illegal items, or even find a missing person. But the dogs first must learn what odors are important to their human partners and how to tell their partners about what they are smelling. We can break down how dogs learn this into four main steps (Figure 3). The learning that occurs at each of these steps does not happen in 1 day-it takes some time. How long it takes depends on the dog and the trainer, and some trainers may do things a little bit differently [2].

\section{Step 1: Associating the Marker With the Reward}

Think back to the example of training a dog to sit. You can imagine that when a dog receives a treat or toy for sitting, the owner might also say something like, "Good!" If this is done often enough, dogs can also learn the association between getting a reward and the word "good." Similarly, when training a working dog, a trainer needs to be able to tell the dog when it is doing something good.

A type of signal that tells an animal that what it has done will be rewarded, either immediately or after a certain period of time.
The words or sounds that trainers use to tell dogs that they are doing something good are called markers. So, a marker tells the dog that what it has done will be rewarded. A marker can be any sound, but many trainers like to use a clicker (a device that produces a clicking sound) or a word, such as "OK."

At the beginning of training, the marker does not mean anything to the dog-it is just a sound. To make the marker important to the dog, the trainer must show the dog over and over again that the marker means a reward is coming. To do this, a trainer can put a toy in front of the dog, but hide it behind his or her hand. If the trainer moves his or her hand, the dog approaches the toy. Right when this happens, the trainer uses the marker ("Ok!"). After doing this many times, the dog learns the association: when the dog hears the marker, it can expect its toy sometime soon. Are you wondering why trainers might use toys instead of a food treat? For working dogs, it is typically safer to keep their food far away from any potentially dangerous items. Also, the dogs really like playing with the toy with the trainers-like a game of tug-of-war-so toys are rewarding, just like food is. 
Figure 2

A dog's nose. When a mammal like a dog sniffs, tiny odor particles bind to areas in the nose. When this happens, signals are sent to the brain, where they are identified (Photo: Creative Commons (C)

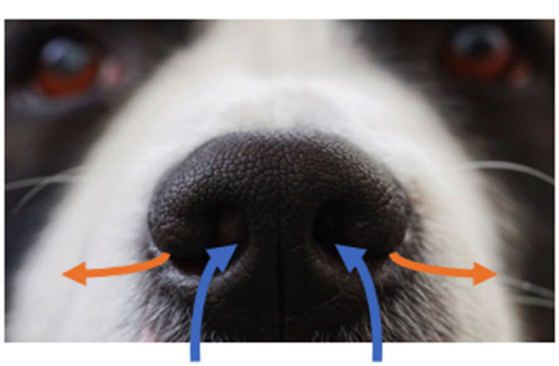

1. Air is exhaled through the sides of the nose, so it doesn't dilute the odor carried in the incoming air.

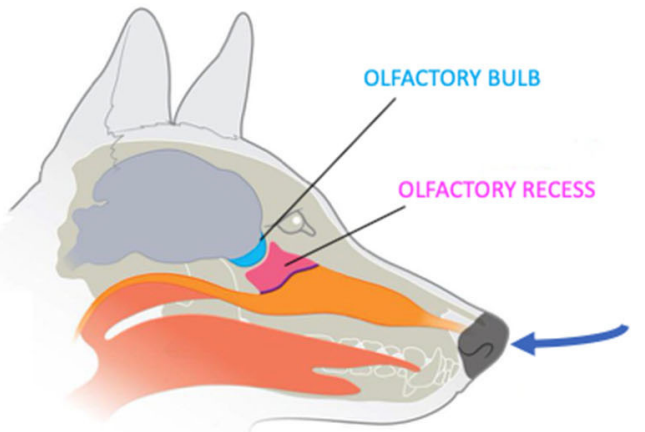

2. The incoming air circulates in the nose, and odor is temporarily trapped in the OLFACTORY RECESS. Once there, the OLFACTORY BULB, a part of the brain, relays the information to complex circuits of other brain areas.

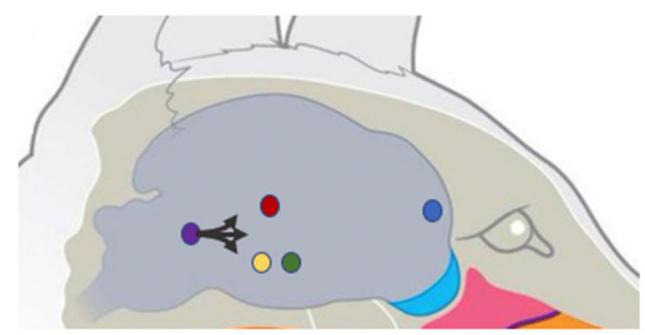

3. If dogs are given a treat or favorite toy after they smell an odor and do a certain behavior, a substance called dopamine travels from a part of the brain called the VENTRAL TEGMENTAL AREA to other brain areas. For example, the NUCLEUS ACCUMBENS is a brain area involved in making the dog feel good. The AMYGDALA is involved in connecting emotions to the environment.

Dopamine is also released at the PREFRONTAL CORTEX, which helps to focus attention, and at the HIPPOCAMPUS, which helps to form memories. So, the dog starts to connect the odor and its own behavior with getting a treat or toythe brain is saying, "This was good; let's do it again!".

\section{Step 2: Learning to Sniff for the Important Odor}

At this point, the dog understands that when it hears the marker, it will get a reward. Now, the trainer needs to teach the dog to sniff out a particular odor among all the other smells in the environment-as if you were asked to use your nose to find a pile of cinnamon among piles of other spices. 
Figure 3

The four steps of training a dog to tell us about an odor. In Step 1 , the dog learns to associate the marker with a toy. In Step 2, the dog learns to sniff for the important odor. In Step 3, the dog learns to explore the environment, using its nose to find the odor. In Step 4, the dog learns to communicate that it has smelled the odor.

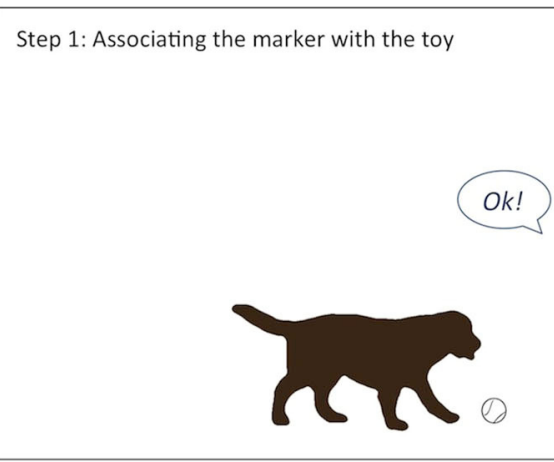

Step 2: Learning to sniff for the important odor
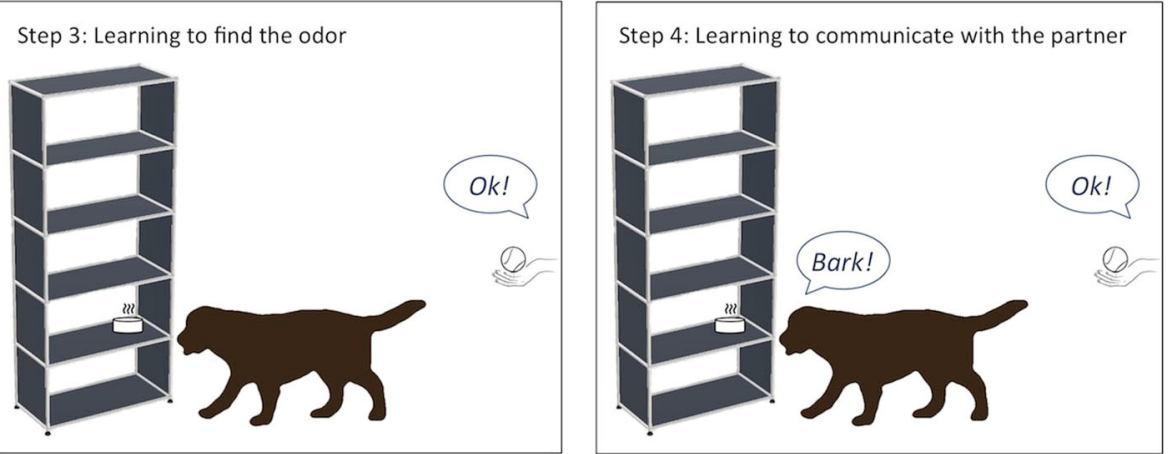

Figure 3

The trainer puts something that has the important odor into a container. The container is then placed near the dog. Dogs are naturally curious and use their noses to explore. So, the dog will soon start to sniff the container. When it sniffs, the trainer uses the marker ("Ok!") and gives the reward to the dog. If the dog sniffs containers that do not have the important odor, it does not hear the marker or get the reward. This can be done over and over again. The dog will learn that it should sniff for a specific scent, because that will lead to a reward. This is another example of learning an association by the process of positive reinforcement.

You might be wondering why trainers do not use a command like "Sniff!" the same way they might use the command "Sit!" for sitting. Because sniffing comes so naturally for dogs, trainers do not always use a command to get the dogs to perform that behavior.

\section{Step 3: Learning to Find the Odor}

The trainer now has to teach the dog that the odor is not always easy to find. When the dog is working, it may need to explore a large area, sniffing everywhere to find the odor. So, to teach this, the trainer can put the container in many different hiding places. After the dog searches and sniffs at the container, the trainer will use the marker. If the dog then returns to the trainer, the trainer will give the toy reward. This can be repeated many times. 
When the dog starts to get good at searching and finding the container, the trainer can slowly start to increase the time between the sound of the marker and letting the dog play with the toy. This is important because, in the real world, the dog's human partner may not be able to reward the dog with the toy immediately. But the partner can use the marker so the dog can anticipate a reward sometime soon.

\section{Step 4: Learning to Communicate With the Partner}

At this point, the dog has learned to explore the environment, searching for the important odor. But, as a final step, the dog needs to learn how to tell its human partner when the odor is found. To do this, it is best to use a dog's natural behavior. For example, some dogs may naturally sit when they smell the important odor and wait to hear the marker. Some other dogs may stare directly at the location of the odor while waiting. When the trainer starts to see the dog's specific behaviors, he or she can start to use the marker and give the toy only when the dog does the behavior after sniffing the correct place. For the dog, the behavior of sitting or staring when it is near the odor becomes associated with the marker and reward, so the dog will begin to do it more often.

All of these training steps can take a long time. Sometimes, trainers may need to repeat a step, or try a new way of teaching so that a dog can learn. But, because dogs pay close attention to humans and want to work with us, many of them can become good working dogs.

\section{WHAT ELSE DO WE NEED TO KNOW?}

Scientists already know a lot about how animals like dogs learn associations between behaviors and rewards. Dog trainers can use this knowledge and their experience to help dogs learn new behaviors-even behaviors important to police work. There is still a lot we do not know about what would help dogs to learn their jobs faster. For example, is it better to teach a police dog about one important odor at a time, or many odors? How do dogs learn about one important odor when it is mixed with other odors? How can you tell if a puppy will become a good working dog? These are big questions about how animals learn that scientists and trainers can work together to solve.

\section{REFERENCES}

1. Hare, B., and Tomasello, M. 2005. Human-like social skills in dogs? Trends Cogn. Sci. 9:439-44. doi: 10.1016/j.tics.2005.07.003

2. Meyer, J. 2019. Episodes 002, 004, \& 008: Marker Training for Detection Dogs Parts 1-3. HITS K-9 Radio: Police Dog Training for Cops by Cops. Available online at: https://hitsk9.podbean.com/e/002-marker-training-for-detection -dogs-part-1/ 
SUBMITTED: 01 August 2019; ACCEPTED: 17 July 2020;

PUBLISHED ONLINE: 28 August 2020.

EDITED BY: Paul William Glimcher, New York University, United States

CITATION: Jones SVR and Kuhlmeier VA (2020) How Do Police Dogs Learn to Do Their Job? Front. Young Minds 8:109. doi: 10.3389/frym.2020.00109

CONFLICT OF INTEREST: The authors declare that the research was conducted in the absence of any commercial or financial relationships that could be construed as a potential conflict of interest.

COPYRIGHT $\odot 2020$ Jones and Kuhlmeier. This is an open-access article distributed under the terms of the Creative Commons Attribution License (CC BY). The use, distribution or reproduction in other forums is permitted, provided the original author(s) and the copyright owner(s) are credited and that the original publication in this journal is cited, in accordance with accepted academic practice. No use, distribution or reproduction is permitted which does not comply with these terms.

\section{YOUNG REVIEWERS}
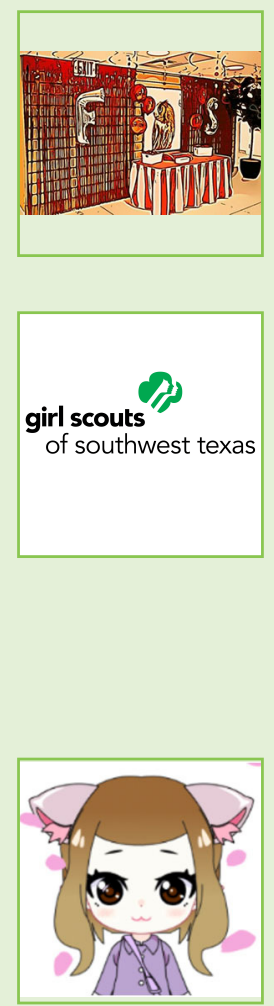

\section{FRIENDS SEMINARY, AGES: 11-13}

Middle School students at Friends Seminary are inquisitive, active, and engaging students who question the world they are a part of in order to bring about a world that ought to be. They enjoy all discussions in science and felt a part of the scientific process given this opportunity!

\section{GIRL SCOUTS OF SOUTHWEST TEXAS, TROOP 66, AGES: 8-13}

Girl Scout troop 66 loves animals, the environment, outdoor activities, and Science Technology Engineering and Math (STEM) activities. Because of this our girls were very excited to learn about scientific publications and to be part of the peer review process through Frontiers for Young Minds. Many of the girls plan to be scientists, doctors, or engineers when they grow up. Most of our adult volunteers (parents) are biomedical or STEM professionals who help foster their continued interest in STEM.

\section{JOSEPHINE, AGE: 12}

I was happy to serve as a young reviewer for Frontiers for Young Minds. I have been a girl scout ever since kindergarten and enjoy all the STEM field trips with my troop. I am a competitive swimmer, I love art and music (piano, violin, and guitar) but more than anything else I love cats. When I grow up I plan to study to be an engineer, possibly electrical or mechanical, but I am not sure yet which kind.

\section{LAUREN, AGE: 13}

I like spending time with animals, especially my dog, Magic, my hamster, Mr. Nibbles, and all of the rescue animals at the Animal Defense League where I volunteer to earn hours for the Girl Scout silver award. I also like to ride horses. I am in eighth grade and my favorite subject is English. In high school and college, I want to learn more about animals so I can work with them for the rest of my life! 

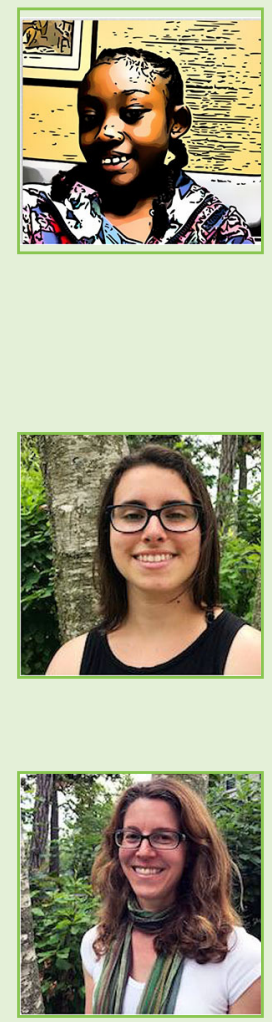

\section{MAHOGANY, AGE: 11}

Girl scouts has lots of troop activities that I like, such as selling cookies, camping, horseback riding, archery, and being with my friends. I have earned a lot of different badges for STEM activities. I love animals of all sorts and volunteering to help them.

\section{AUTHORS}

\section{SARA V. R. JONES}

I am an undergraduate student studying psychology and sociology at Queen's University in Kingston, Ontario, Canada. I enjoy trying to figure out how different species think and learn, as well as how people and other animals create social relationships. I hope to continue studying these two subjects as a graduate student.

\section{VALERIE A. KUHLMEIER}

I am a Professor at Queen's University in Kingston, Ontario, Canada. I lead a lab that does research on how children and animals think and learn. I also teach classes on these topics. When I am not teaching or doing research, I like to spend time with my partner and my dog. Lately, I have been very interested in training my dog to detect odors and track scents in the neighborhood. *vk4@queensu.ca 